Covered in: Web of Sciences (WOS); EBSCO; ERIH+; Google Scholar; Index Copernicus; Ideas RePeC; Econpapers; Socionet; CEEOL; Ulrich ProQuest; Cabell, Journalseek; Scipio; Philpapers; SHERPA/RoMEO repositories; KVK; WorldCat; CrossRef; CrossCheck

2018, Volume 10, Issue 1, pages: 54-61 | doi: https://doi.org/10.18662/rrem/17

\section{Actual Playing Time in the Senior Football \\ Championship of Romania, League I}

\author{
Sorin Mirel CIOLCA ${ }^{* 1}$, \\ Gheorghe GRIGORE ${ }^{2}$, \\ Tudor PALADE ${ }^{3}$
}

${ }^{1}$ UNEFS, Bucureşti, România, sorin.ciolca@yahoo.com

Corresponding author

${ }^{2}$ UNEFS, Bucureşti, România, gh.grigore@yahoo.com

${ }^{3} \mathrm{UNEFS}$, Bucureşti, România, paladetudor@yahoo.com

\begin{abstract}
Actual playing time is an important problem in the progress of a football game, with implications in both the scientific guidance of the training process and the achievement of superior results. The issue addressed in this research is useful, because it has been noticed that, in the official games played by seniors, a lot of time is wasted on:

- fixed moments (phases) - throw-in, corner kick, direct and indirect free kicks, referee's ball, kick-off;

- substituting players;

- player injuries during games;

- solving unexpected situations - the entry of a supporter on the field, the existence of several balls on the field, as well as the discussions between referees and technical staff members. One of the important features of current football, the game dynamics, is also highlighted by a significant number of technical and tactical actions. In this regard, actual playing time must be as long as possible to the detriment of breaks and fragmentations occurred during games. In the context of major competitions - European cups, European Championship and World Championship, there is a visible trend to increase the actual playing time, which can be achieved by using, in the training of football players, some rationalized and standardized methods and means with increased efficiency.
\end{abstract}

Keywords: training, football, stoppage time, actual playing time, lost time.

How to cite: Ciolca, S.M., Grigore, G., \& Palade, T. (2018). Actual playing time in the Senior Football Championship of Romania, League I. Revista Romaneasca pentru Educatie Multidimensionala, 10(1), 54-61. https://doi.org/10.18662/rrem/17 


\section{Introduction}

Actual playing time is an important problem in the progress of a football game, with implications in both the scientific guidance of the training process and the achievement of superior results.

The International Football Association Board (IFAB), the governing body that establishes the laws of football game, considers the possibility of major changes that revolutionise the most popular sport.

The main measure they want to implement refers to the match duration, which they intend to reduce from $\mathbf{9 0}$ to $\mathbf{6 0}$ minutes. But the time would be the actual one, meaning that only the moments when the ball is in play would be timed.

If the match duration is reduced to just 60 minutes, the timer might be stopped in several situations, such as awarding a free kick or a penalty kick (from the moment it has been awarded to the moment of execution), making a substitution, scoring a goal (from the moment of scoring until the game is restarted from the middle of the field) or the injury of a player.

One of the important features of current football, the game dynamics, is also highlighted by a significant number of technical and tactical actions. In this regard, actual playing time must be as long as possible to the detriment of breaks and fragmentations occurred during games.

\section{Problem Statement}

The aim of the top-performance football game is to offer an agreeable show characterised by optimal game dynamics and meant to attract millions of spectators and viewers.

The density of technical and tactical actions in attack and defence creates the favourable environment for the sports show. But what is density? In sport, density is the ratio between motor activity and the time unit. Regarding this issue, in the game of football, the density of players' motor actions highlights the actual playing time.

In the context of current football, the actual playing time is particularly important, and its analysis can contribute to the scientific guidance of training and the creation of a highly competitive environment.

The models extracted from the games played in the advanced football championships of Europe provide a real picture through which we can achieve comparative studies on the actual playing time, the number of stoppages and the time lost because of them. 
The topic addressed in this research has also been investigated by other high-performance football specialists, such as Hamilton H. (Hamilton, 2015), who conducted a study setting the ratio between the values of actual playing time and the number of official games in the Premier League.

Actual playing time also depends on the additional time set by the referee at the end of each half. It increases as the additional time is longer (Prüßner \& Siegle, 2015).

\section{Research Questions/Aims of the research}

The research had the following objectives:

- to determine the actual playing time in the official games of the Romanian Senior Championship, League I, edition 2017-2018;

- to objectify the proposal of the International Football Association Board (IFAB) to change the game rules regarding the match duration (60 minutes of actual playing time).

\section{Research Methods}

We used the following research methods:

- observation - it consisted in capturing the situations and the appropriate moment to interrupt the viewed games;

- recording - we recorded the time lost through game interruptions (fixed game moments, player substitutions, player injuries/ unexpected situations) in 42 official matches, Senior League I of Romania;

- statistical and mathematical processing - to efficiently process and interpret the research data, we used the arithmetic mean and percentage expression;

- graphical representation - the recorded average values of lost time due to interruptions occurring in the viewed games were highlighted by drawing graphs.

\section{Findings}

In order to determine the actual playing time, we recorded the lost time caused by all interruptions in the 42 viewed games played in the first 17 stages of the Senior Championship, League I, edition 2017-2018. The games were played in Bucharest (by the FCSB and Dinamo teams), Chiajna (by the Concordia Chiajna team), Ploiesti (by the Iuventus Bucharest team) and Voluntari (by the FC Voluntari team). In these games, 102 goals were scored (an average of 2.42 goals per match). 
There were recorded the following average values for the time lost through game interruptions per half and throughout the duration of viewed games (we considered that the average game duration was 93 minutes, plus the additional time awarded by the referee at the end of each half).

Table 1. Average - Lost time (42 games)

\begin{tabular}{cccc}
\hline Fixed moments & $\begin{array}{c}1 \mathrm{st} \mathrm{half}-\text { L.T. } \\
(\mathrm{min} .)\end{array}$ & $\begin{array}{c}\text { 2nd half }- \text { L.T. } \\
(\mathrm{min} .)\end{array}$ & $\begin{array}{c}\text { TOTAL }- \text { L.T. } \\
(\mathrm{min} .)\end{array}$ \\
\hline Corner kick & $1 \mathrm{~min} .30 \mathrm{sec}$. & $2 \mathrm{~min} .17 \mathrm{sec}$. & $3 \mathrm{~min} .47 \mathrm{sec}$. \\
\hline Throw-in & $1 \mathrm{~min} .53 \mathrm{sec}$. & $2 \mathrm{~min} .40 \mathrm{sec}$. & $4 \mathrm{~min} .33 \mathrm{sec}$. \\
\hline Direct free kick & $1 \mathrm{~min} .20 \mathrm{sec}$. & $2 \mathrm{~min} .21 \mathrm{sec}$. & $3 \mathrm{~min} .41 \mathrm{sec}$. \\
\hline Indirect free kick & $2 \mathrm{~min} .04 \mathrm{sec}$. & $4 \mathrm{~min} .20 \mathrm{sec}$. & $6 \mathrm{~min} .24 \mathrm{sec}$. \\
\hline Goal kick & $1 \mathrm{~min} .40 \mathrm{sec}$. & $4 \mathrm{~min} .09 \mathrm{sec}$. & $5 \mathrm{~min} .49 \mathrm{sec}$. \\
\hline Kick-off & $1 \mathrm{~min} .33 \mathrm{sec}$. & $2 \mathrm{~min} .05 \mathrm{sec}$. & $3 \mathrm{~min} .38 \mathrm{sec}$. \\
\hline $\begin{array}{c}\text { Player } \\
\text { substitution }\end{array}$ & $1 \mathrm{~min} .10 \mathrm{sec}$. & $2 \mathrm{~min}$. & $3 \mathrm{~min} .10 \mathrm{sec}$. \\
\hline Injury & $1 \mathrm{~min} .53 \mathrm{sec}$. & $2 \mathrm{~min} .58 \mathrm{sec}$. & $4 \mathrm{~min} .51 \mathrm{sec}$. \\
\hline $\begin{array}{c}\text { TOTAL - T.P. } \\
\text { (min.) }\end{array}$ & $13 \mathrm{~min} .03 \mathrm{sec}$. & $22 \mathrm{~min} .50 \mathrm{sec}$. & $35 \mathrm{~min} .53 \mathrm{sec}$. \\
\hline Percentage & $36.3 \%$ & $63.7 \%$ & $100 \%$ \\
\hline
\end{tabular}

\section{Time lost through fixed moments}

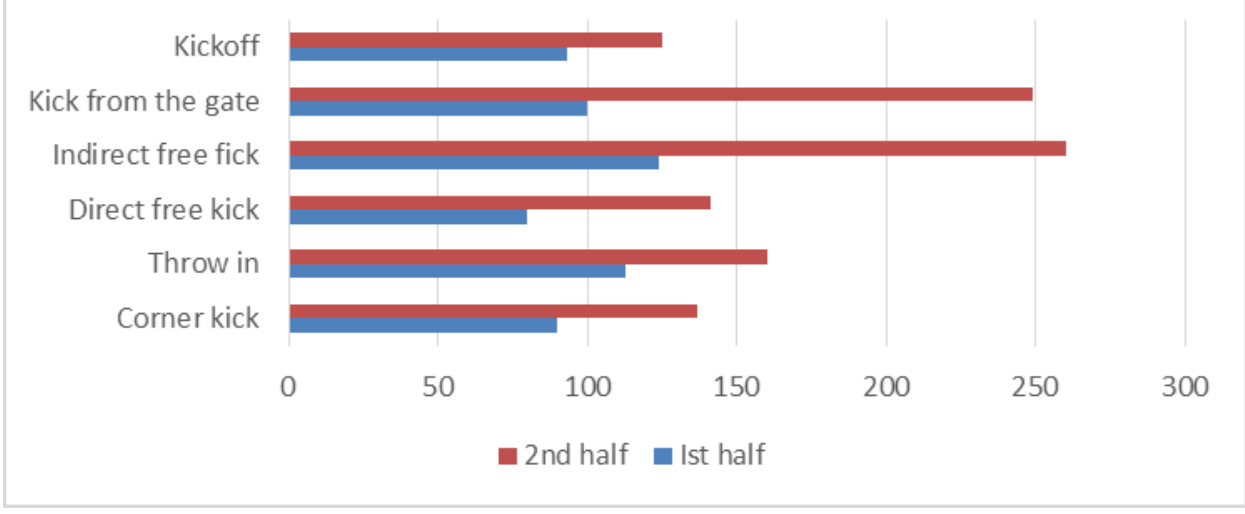

Graph 1 - Time lost through fixed moments

Graph 1 shows that the arithmetic mean values for the lost time are higher in the second half for indirect free kicks, goal kicks and throw-ins. 
For all the fixed moments, the arithmetic mean values recorded in the first half are lower than those recorded in the second half.

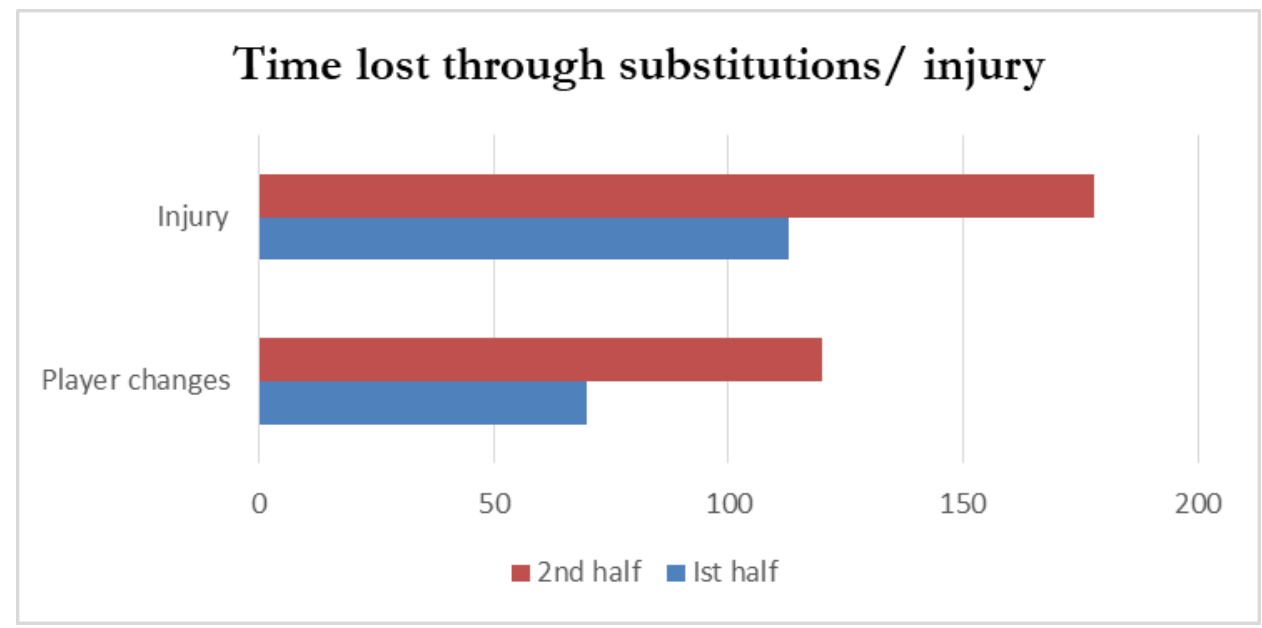

Graph 2 - Time lost through substitutions/ injury

Graph 2 shows that the arithmetic mean values recorded in both situations are close, but those obtained in the second half for injuries/ unexpected situations are higher. This is due to the small number of substitutions and injuries in the first half.

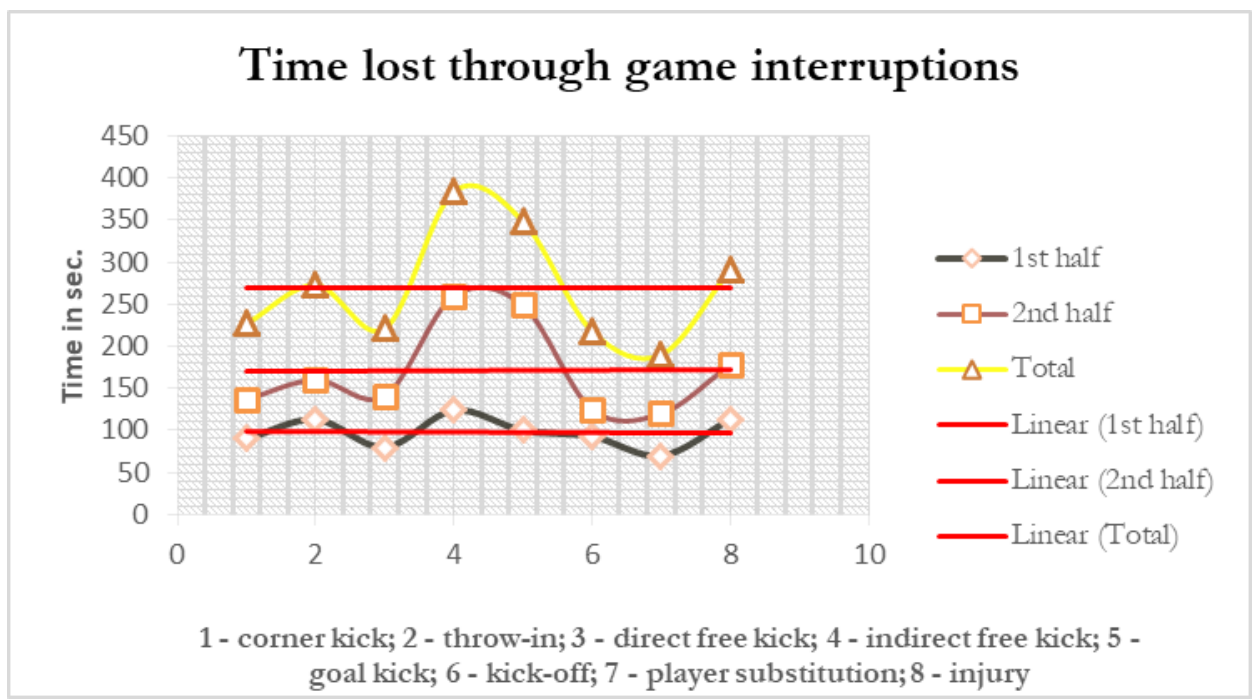

Graph 3 - Time lost through game interruptions 
Graph 3 shows the overall values of lost time due to game interruptions, higher values being recorded for indirect free kicks, goal kicks and throw-ins. The lowest values were recorded for player substitution, kickoff and direct free kick. The lost time values recorded in the second half justify the players' effort to keep the result and the onset of their fatigue towards the end of the game.

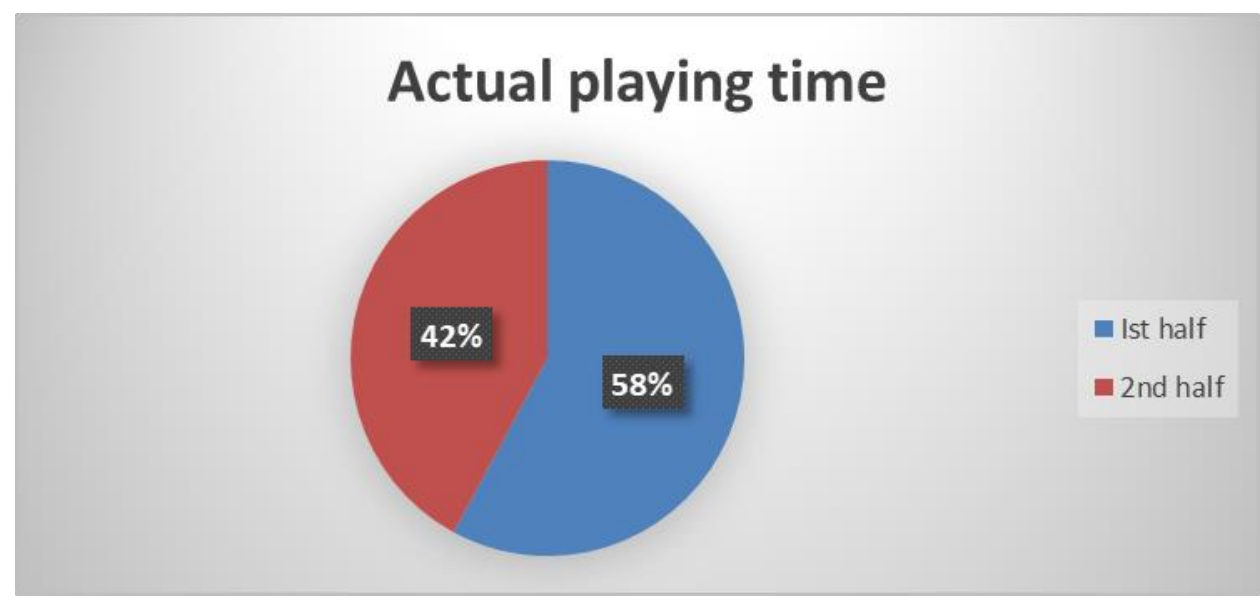

Graph 4 - Actual playing time

The average actual playing time (Graph 4) was calculated by subtraction from the average game time of 93 minutes (additional time at the end of each half - 1 minute and 30 seconds). We obtained the following percentages: $42 \%$ for the first half ( 33 minutes and 27 seconds) and 58\% for the second half ( 24 minutes and 20 seconds). It has been noted that the final value of average actual playing time for the recorded games was 57 minutes and 47 seconds. In the viewed games, a goal was scored at an average actual time of 24 minutes and 27 seconds.

\section{Discussions}

The research results demonstrate the tactical purpose of game stoppages, for instance goal kicks of the leading team take longer towards the end of the match (Siegle \& Lames).

The complex physical, technical and tactical training of the players leads to an improvement in their efficiency during competitions, but also to an increase in the actual playing time (Cojocaru, 2002)

At the 2014 World Championship final tournament, it has been found that the use of spray by the referee at the free kicks (for keeping the 
defenders at a legal distance and positioning the ball) and the number of injuries requiring medical intervention reduced the actual playing time (Augste \& Cordes, 2016)

Taking into account that the average actual playing time is over 60 minutes in the strong championships of Europe (in England, Spain, Italy, Germany), the actual playing time recorded in the Senior Championship of Romania, League I, can be considered relatively good, in our opinion.

We argue this issue by the significant differences between the physical training of the Romanian football players and that of the top-team players, between their technical and tactical performance, between the attitude and mentality highlighted in training and competition by our players compared to foreign football players.

Thus, we believe that the proposal of the International Football Association Board (IFAB) to change the game rules regarding the match duration (60 minutes of actual playing time) is efficient for the domestic championship matches, leading to an improved football show and an increased game dynamics, which will result in attracting spectators and viewers.

\section{Conclusions}

- From the recorded data, we have found that the actual playing time is reduced by approximately 9 minutes in the second half of the game compared to the first half, a difference which can be mainly explained by the "time-wasting" used by players at the end of the match in order to keep the result;

- The fixed moments where most time was wasted were: indirect free kicks, throw-ins, injuries/ unexpected situations;

- Regarding the initiative of the International Football Association Board (IFAB) to regulate the actual playing time to 60 minutes, we believe that the average duration of actual playing time recorded in League I (57 minutes and 47 seconds) is real in the context of current football;

- In favour of increasing the actual playing time, if the proposal of the International Football Association Board (IFAB) to change the game duration does not apply, we think it would be appropriate to extend videorefereeing to all official games, but by setting a limited number of interventions per half for each team in order to analyse the controversial phases. 
Actual playing time in the Senior Football Championship of Romania, League I Sorin Mirel CIOLCA, Gheorghe GRIGORE, Tudor PALADE

\section{References}

Augste, C., \& Cordes, O. (2016). Game stoppages as a tactical means in soccer - a comparison of the FIFA World Cups 2006 and 2014. . International Journal of Performance Analysis in Sport, 16(3), 1053-1064 doi:https://doi.org/10.1080/24748668.2016.11868947

Cojocaru, V. (2002). Fotbal. Notiuni generale. Bucuresti: Axis Mundi.

Hamilton, H. (2015). Effective time in football. 2013. Retrieved from http://www.soccermetrics.net/team-performance/effective-time-infootball

Prüßner, R., \& Siegle, M. (2015). Additional Time in Soccer - Influence of League and Referee. International Journal of Performance Analysis in Sport, 15(2), 551-559. doi:https://doi.org/10.1080/24748668.2015.11868813

Siegle, M., \& Lames, M. Game interruption in elite soccer. Journal of Sports Sciences, 30(7). doi:https://doi.org/10.1080/02640414.2012.667877 